\title{
DA SENSAÇÃO DE ELASTICIDADE QUANDO SE MARCHA SOBRE CADÁVERES
}

Natural de Formiga, Minas Gerais. Vive e trabalha em Belo Horizonte. Dedica-se ao desenvolvimento de trabalhos que transitam entra as linguagens, com ênfase em performance, escultura $e$ instalação. Com formação em Artes Plásticas - bacharelado em Artes Plásticas na Escola Guignard (UEMG) - e outras áreas do saber - estudou medicina na Faculdade de Medicina da UFMG e bacharelado (incompleto) em Design Gráfico (UEMG). Estudou canto popular na Babaya Casa de Canto (2005-2009) e canto lírico (2009-2019) com Marilene Gangana, Neyde Ziviani e Sergio Anders. Desenvolve atualmente sua pesquisa em artes visuais no atelier ESPAl, em Belo Horizonte. Participou do grupo do Háptico de Sonia Laboriau, na escola Guignard, em 2007-2008 e do grupo de estudos e orientação de projetos com Solange Pessoa, em 2008. Fundador da plataforma Glory Hole, dedicada a experimentações de linguagens, sem categoria nem classificação. Em 2008 realiza a performance "Triângulo das delícias" no Instituto Inhotim. Em 2010 participa do filme "petit a" de Dora Longo Bahia, dentro do projeto Destricted.br e no mesmo ano recebe o convite de Marco Paulo Rolla para participar de suas performances, durante uma semana consecutiva de performances, na mostra dos terreiros da $29^{\mathrm{a}}$ Bienal de São Paulo. Participou da residência artística CA-BRA (Centro América - BRAsil), em 2011, com jovens artistas de toda a América Latina. Em 2013 realiza sua primeira performance no a América Latina. Em 2013 realiza sua primeira performance no mostra "Da morte e do amor - proposições de um aniquilamento do outro" inaugura a galeria Periscopio Arte Contemporânea em 2015. Deixa a galeria em 2017 e retoma sua poética baseada na diluição do corpo, na sublimação do objeto e na revivificação de símbolos decadentes. Foi finalista do Prêmio Pipa em 2020. 


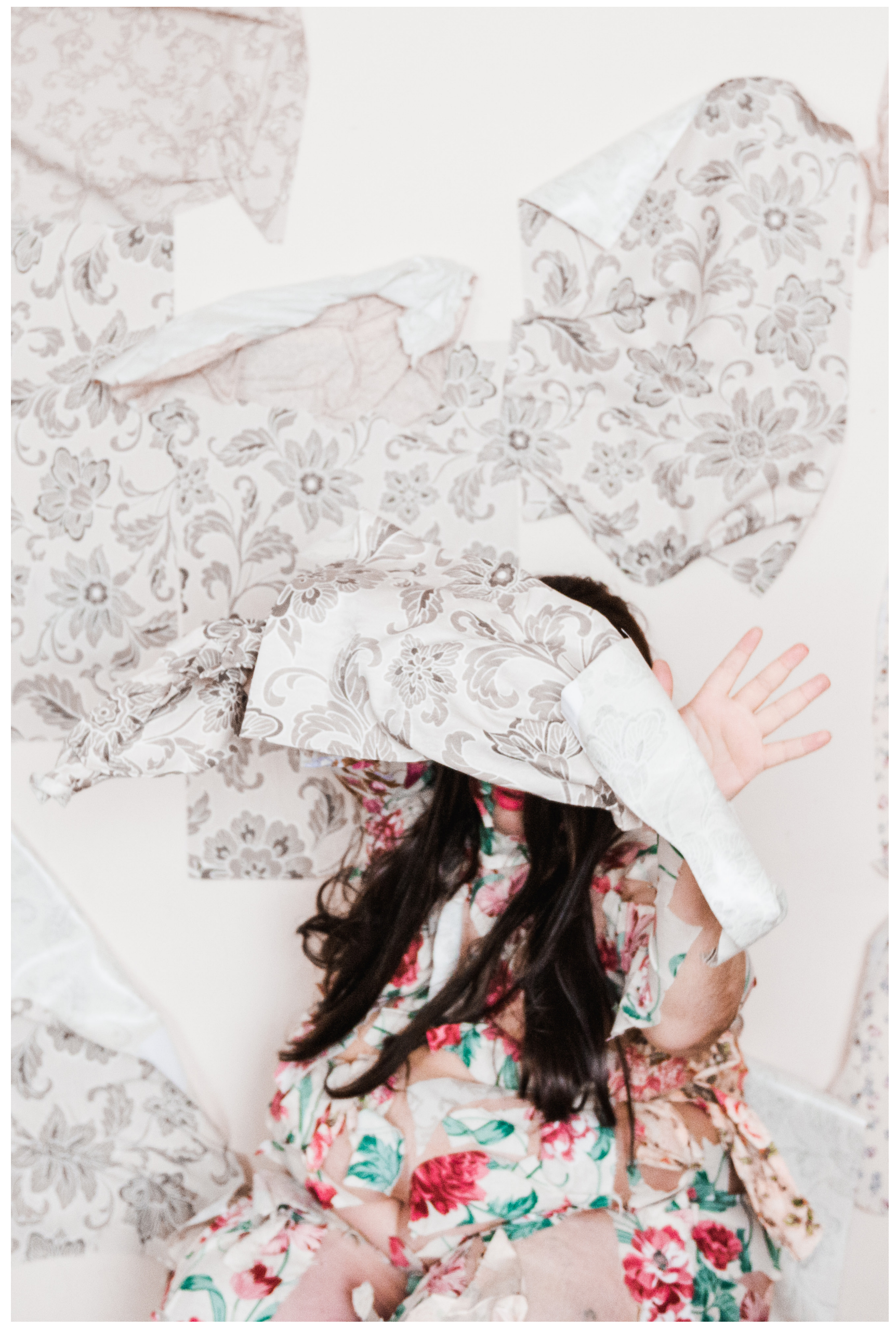




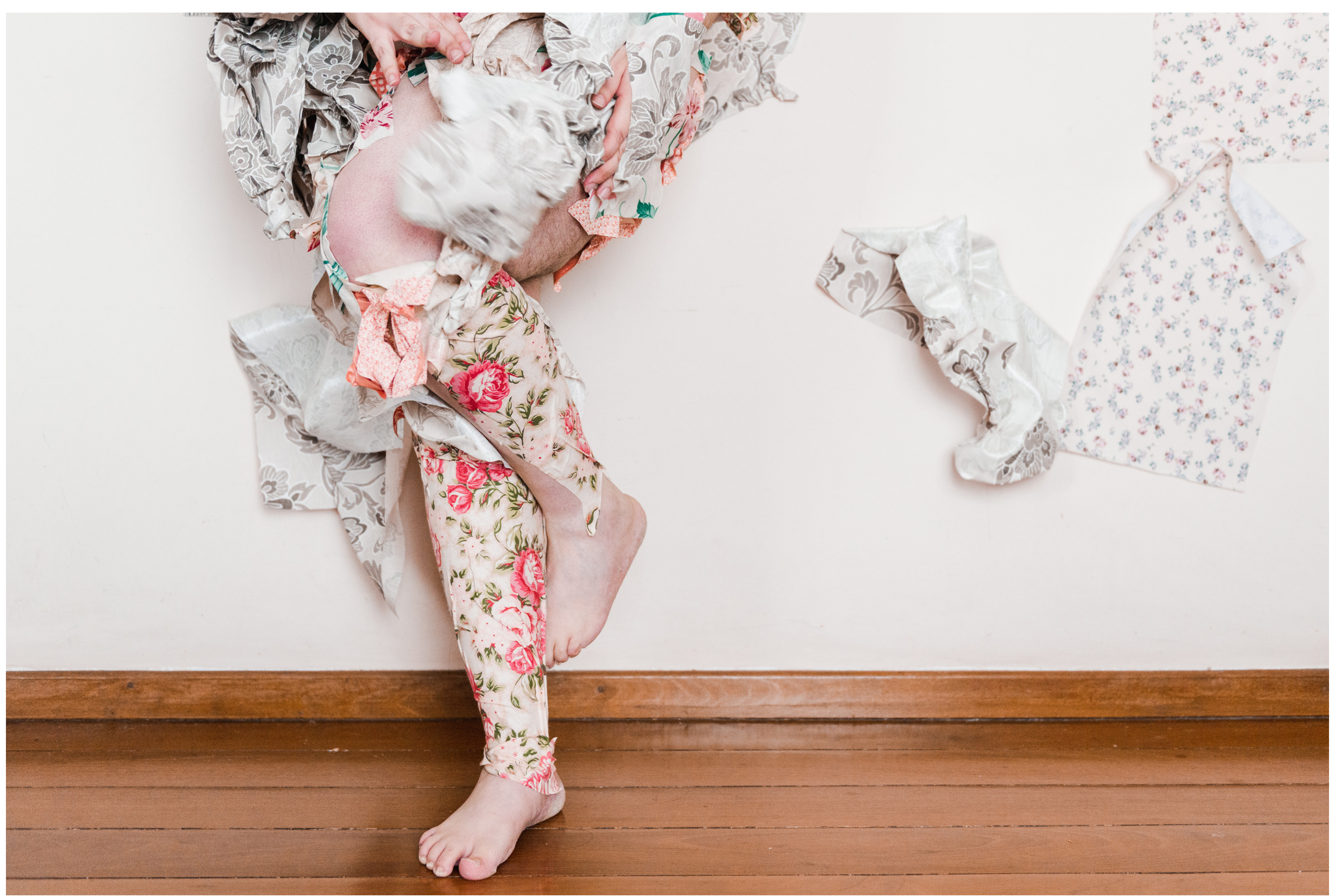




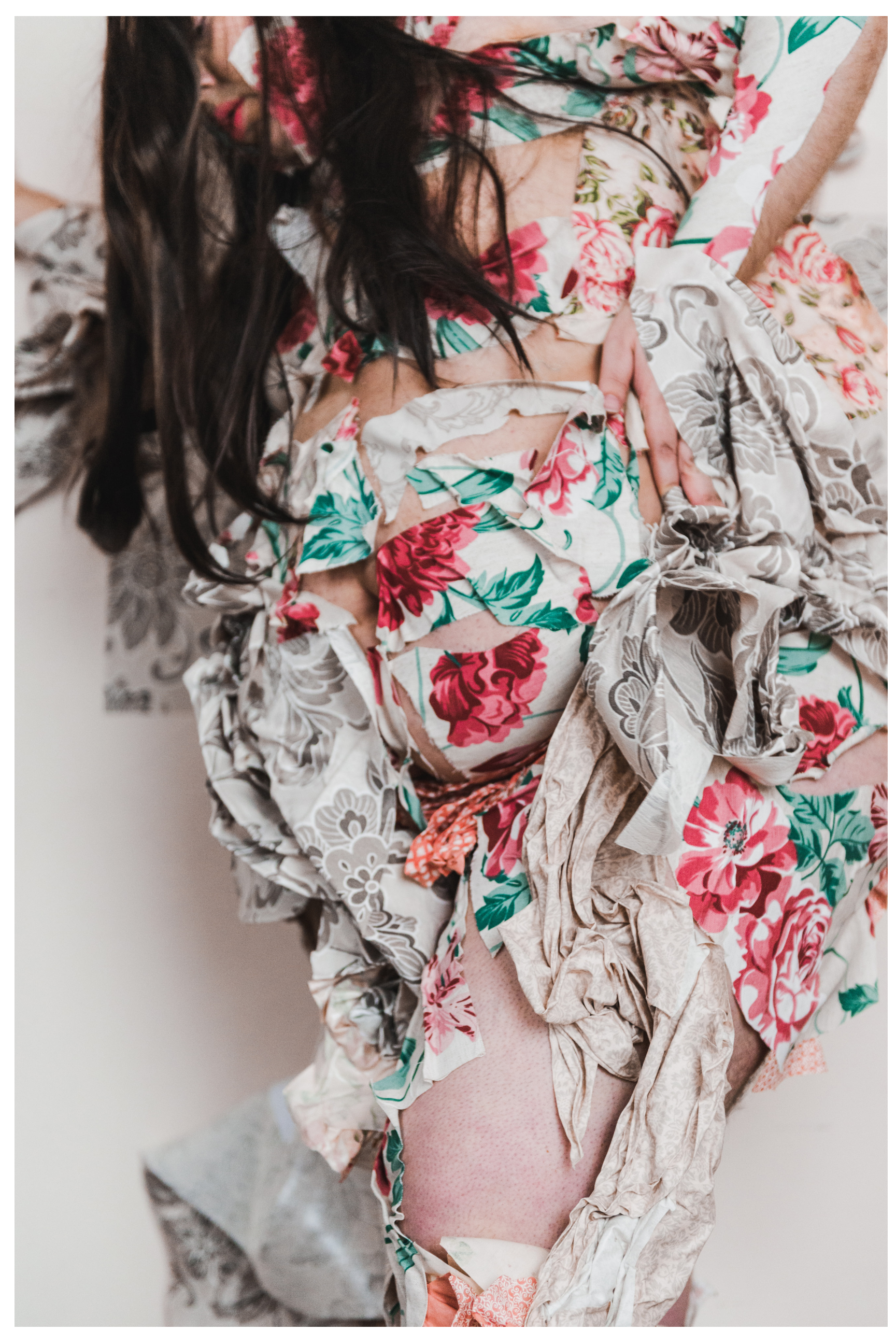




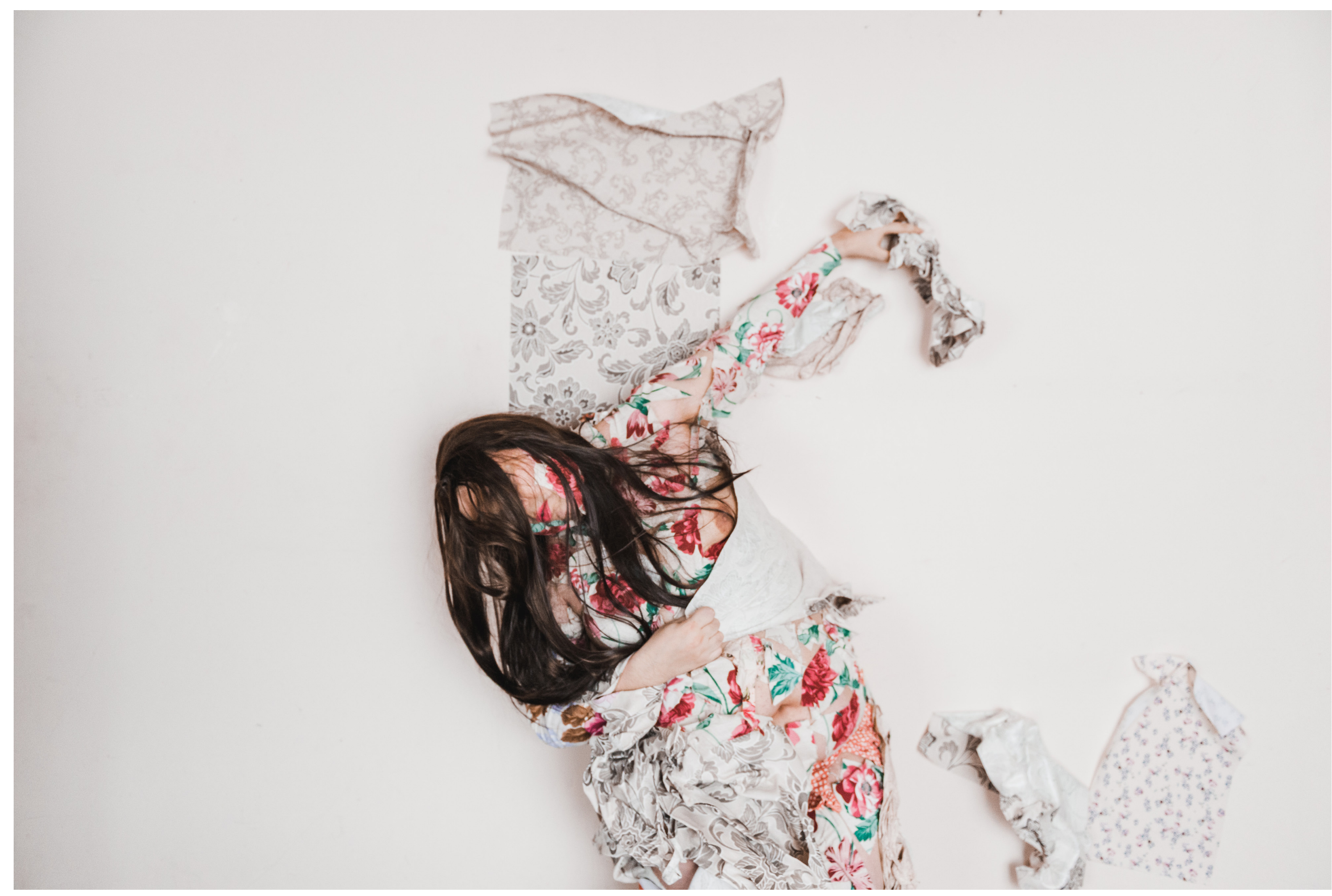




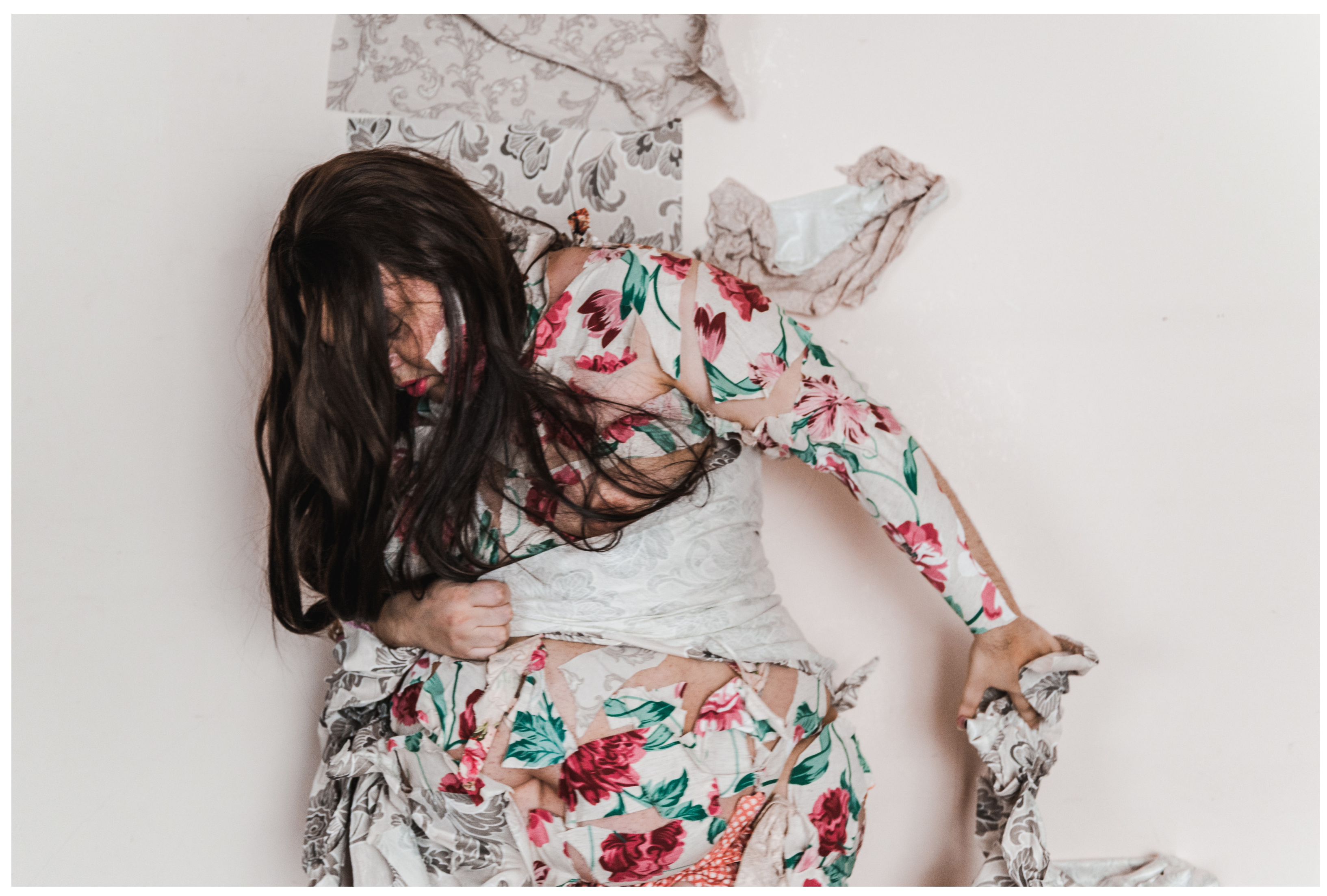




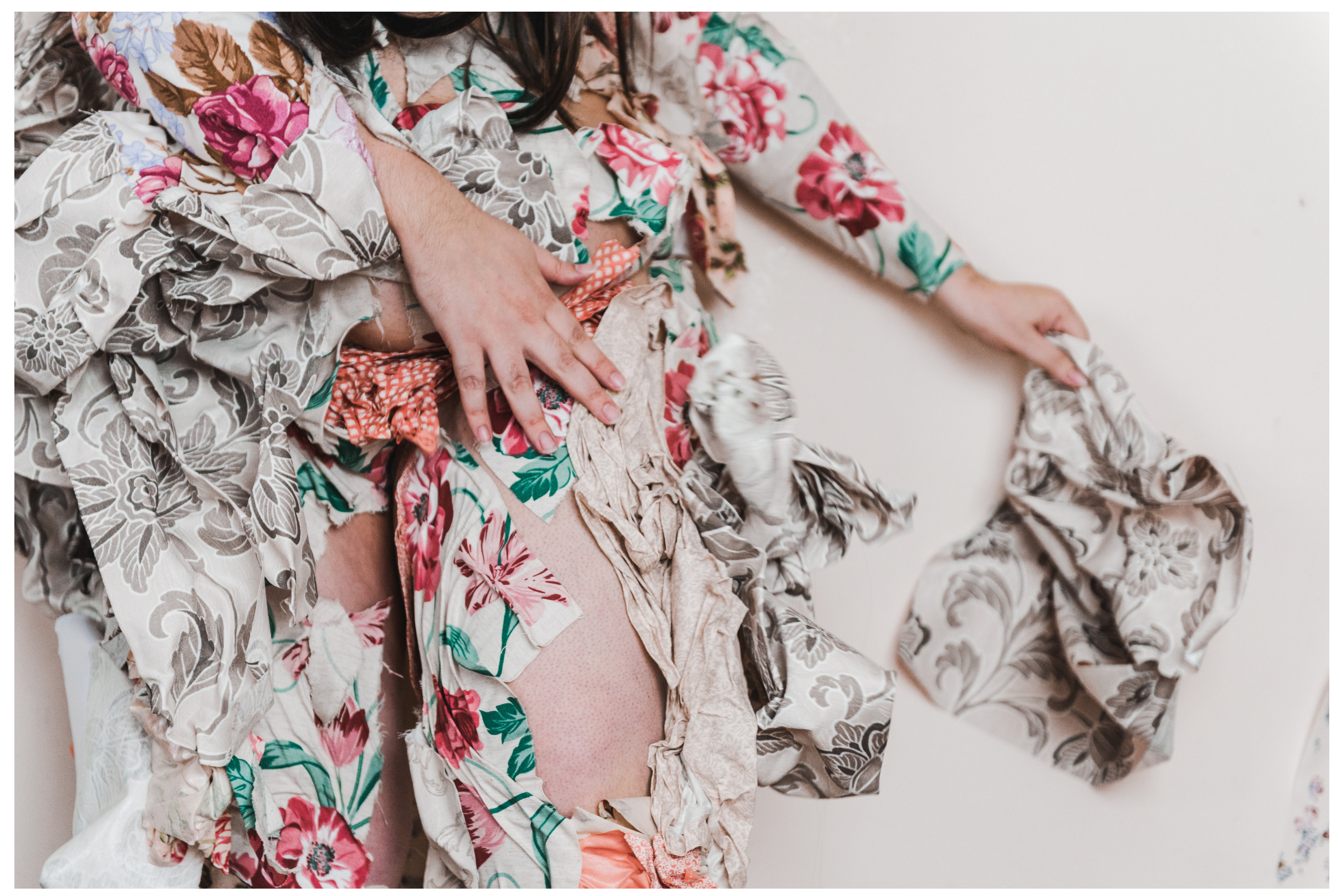




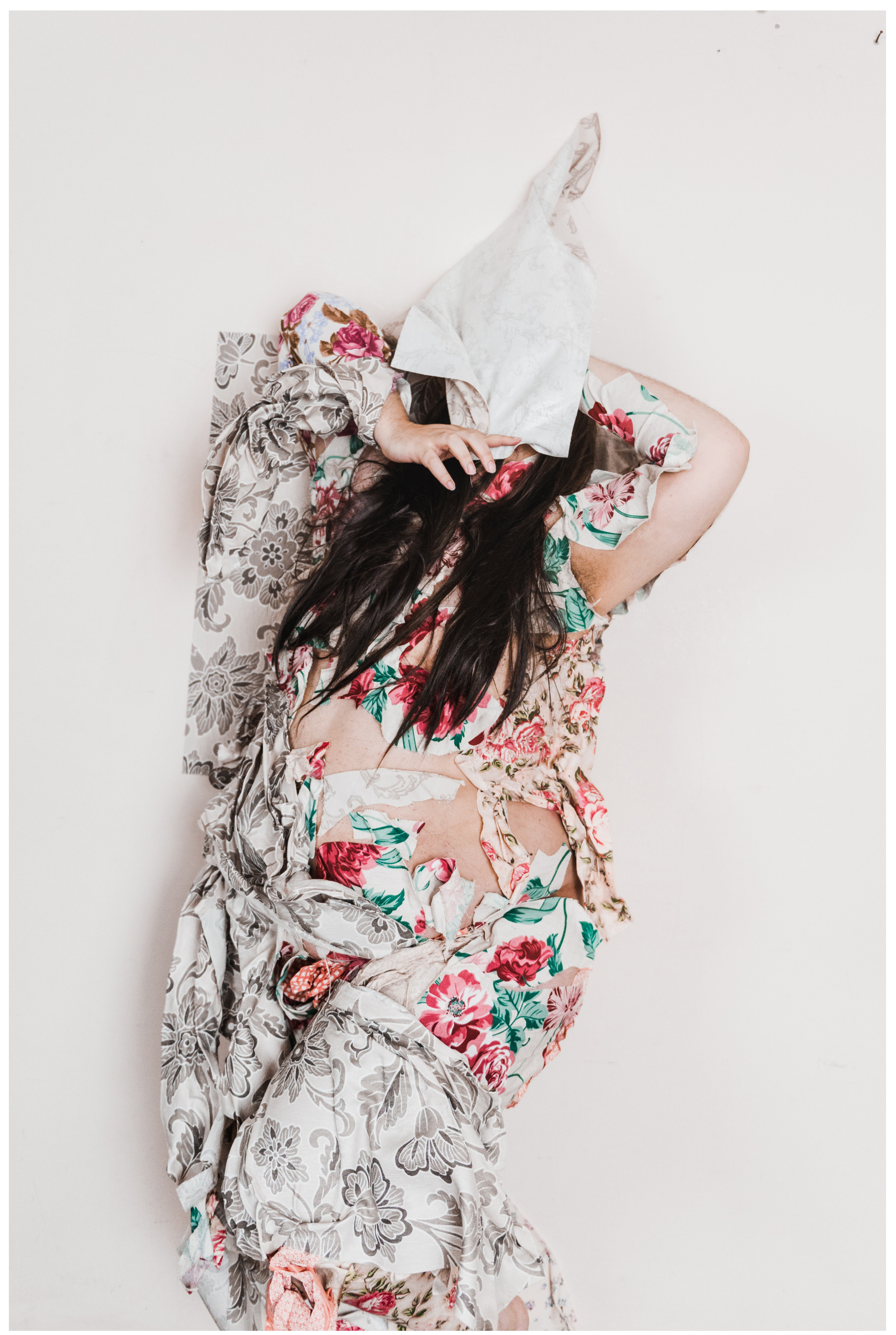




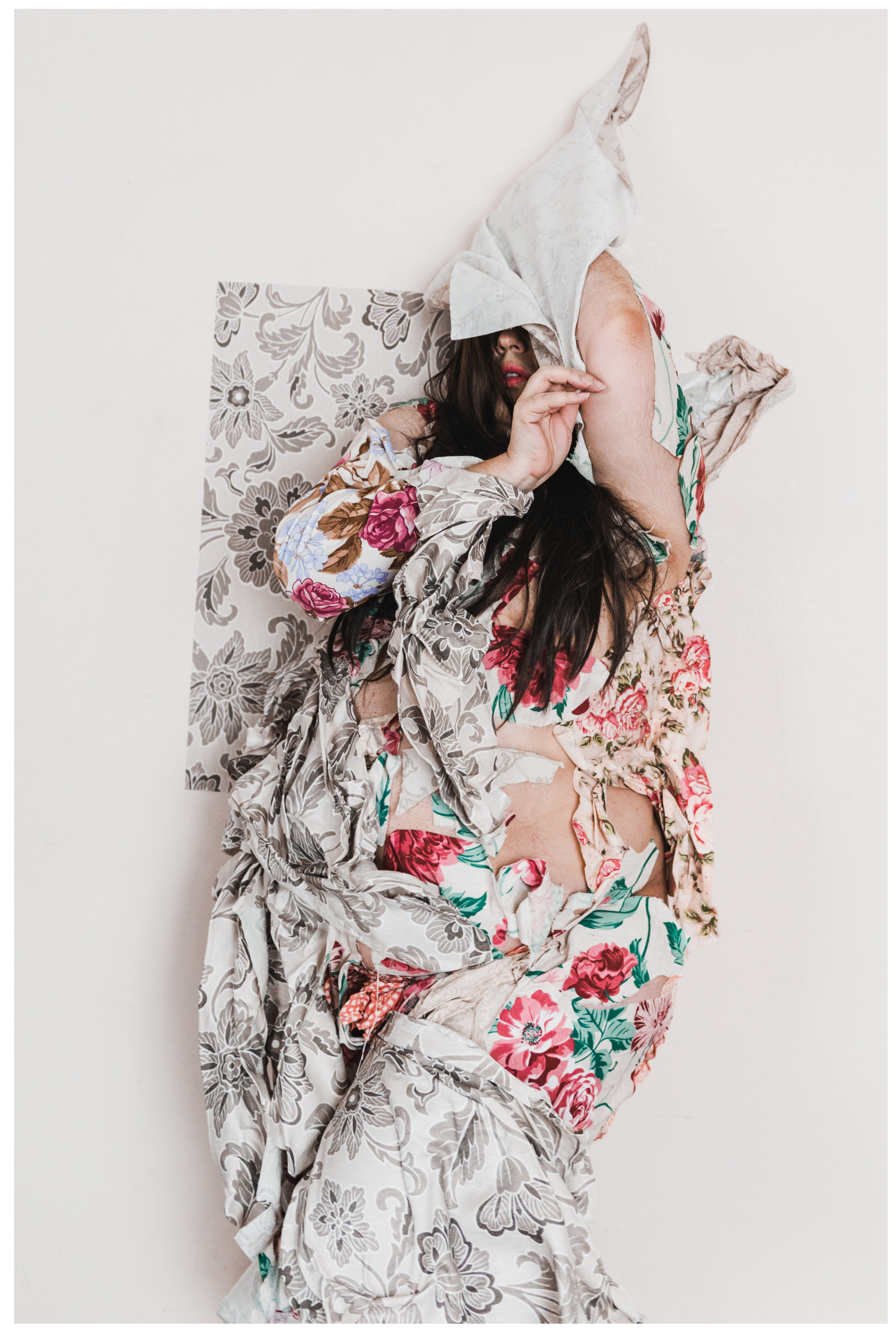




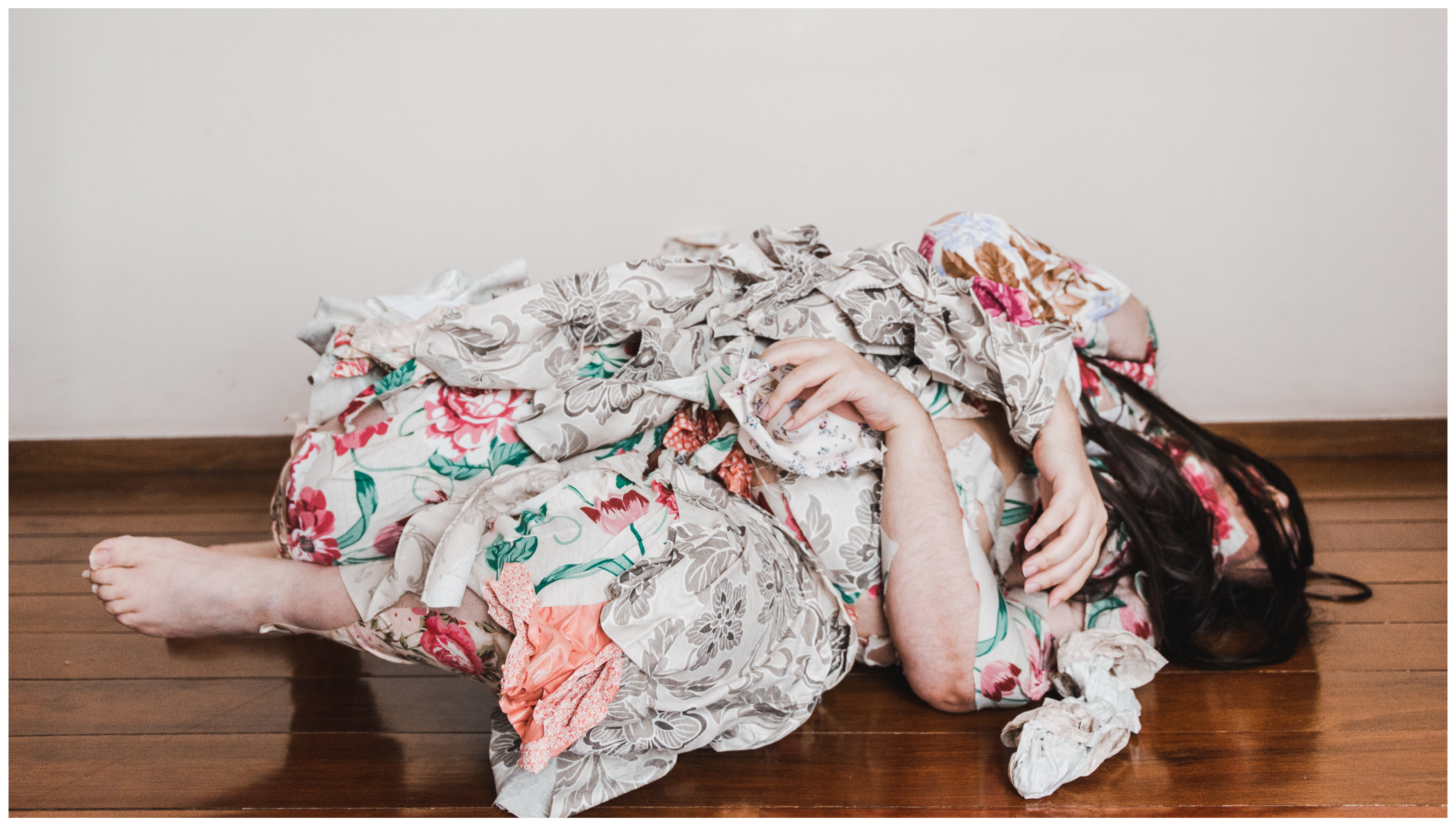




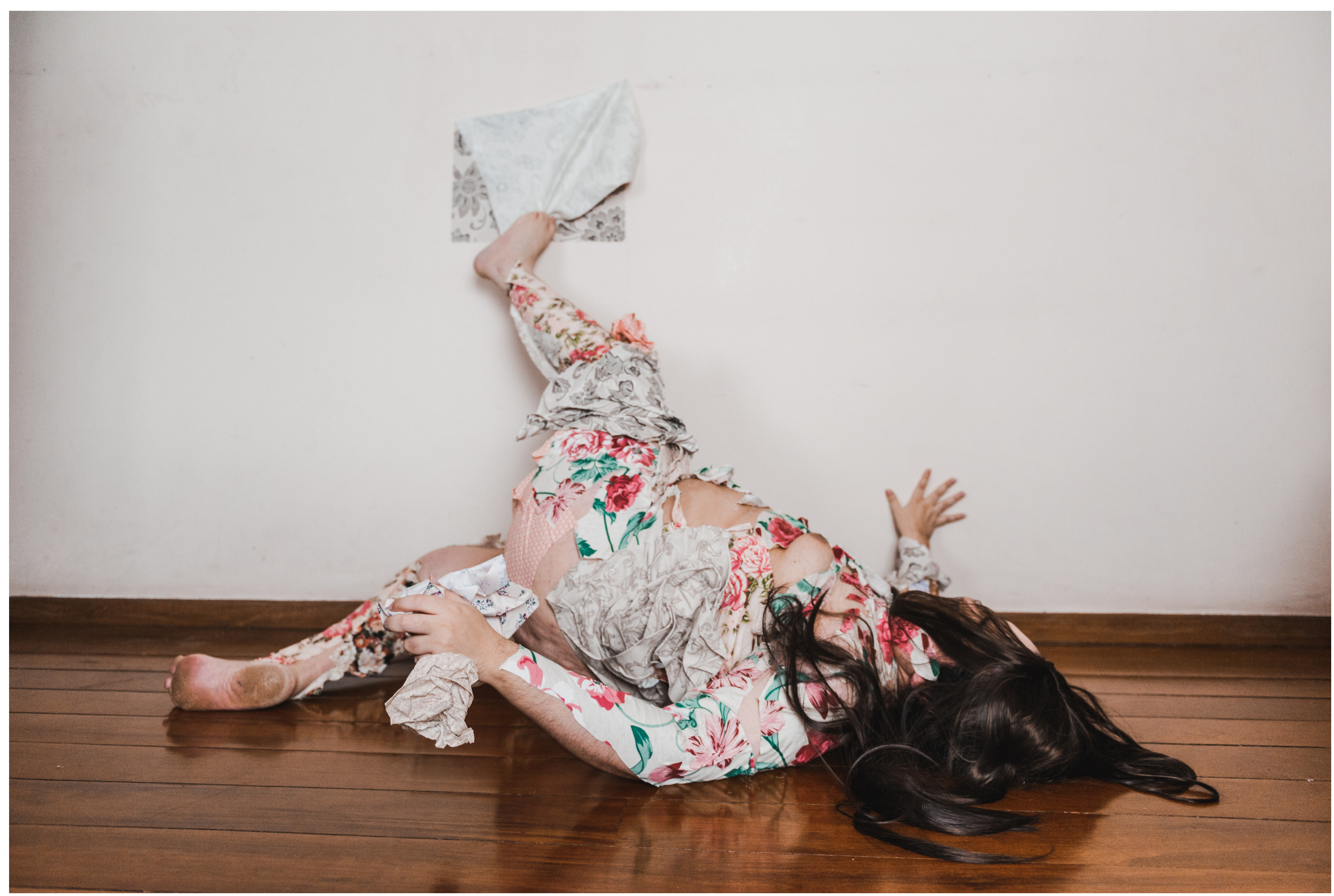




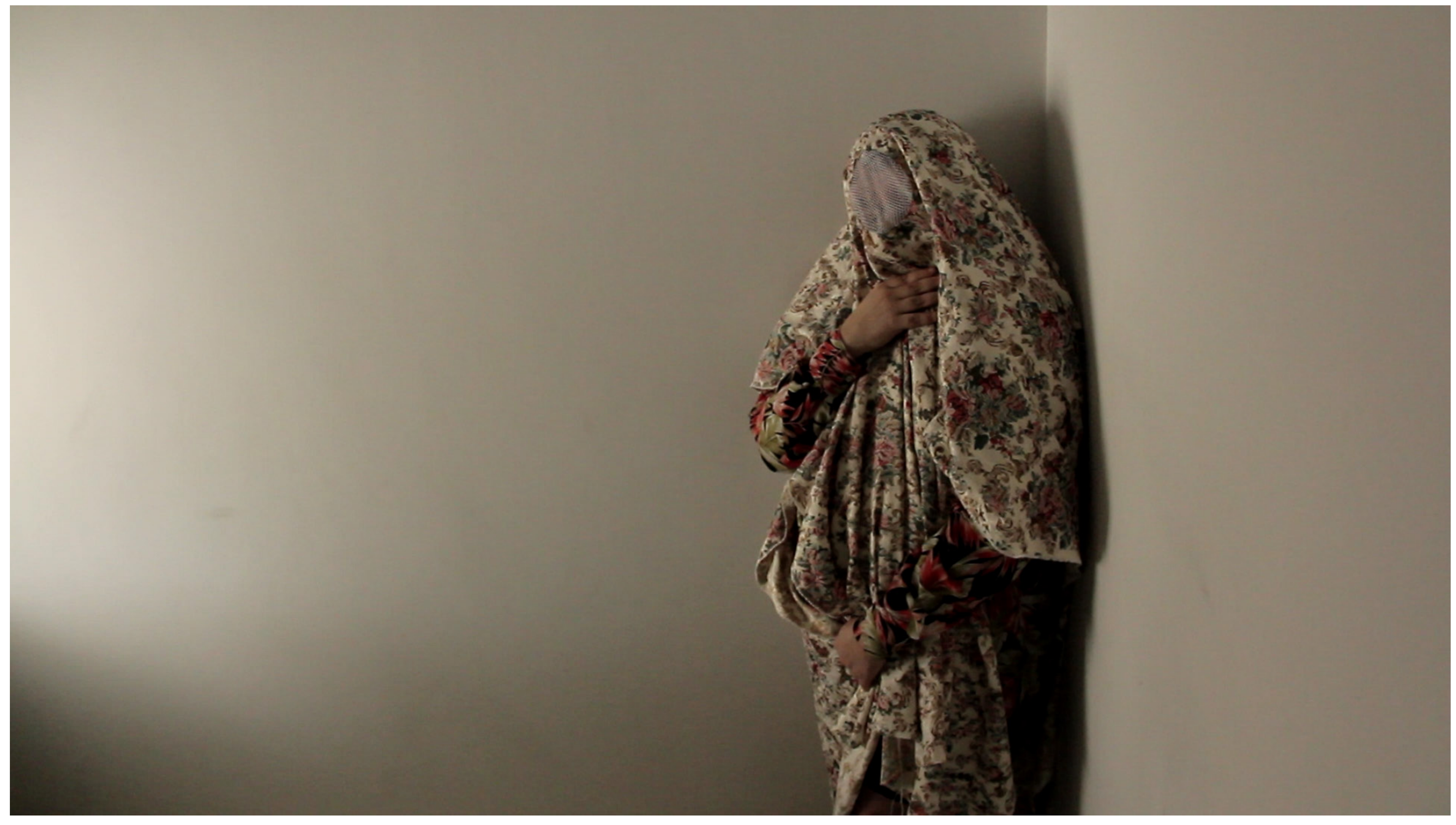




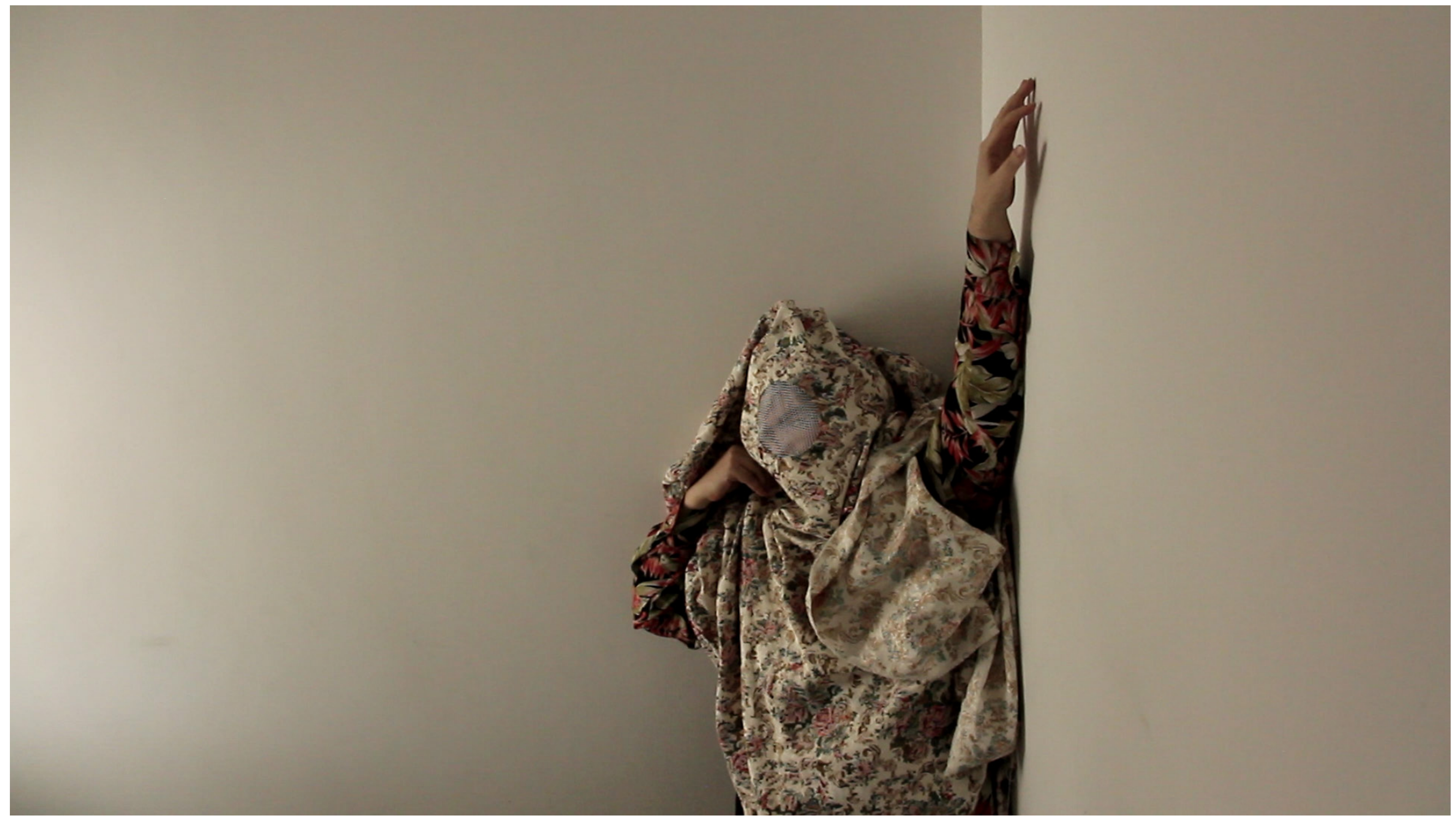

